\title{
(6) OPEN ACCESS \\ Performance enhancing drug abuse and cardiovascular risk in athletes: implications for the clinician
}

${ }^{1}$ Research Institute for Sport and Exercise Sciences, Liverpool John Moores University, Liverpool, UK ${ }^{2}$ School of Sport and Exercise Science, University of Bedfordshire, Bedford, UK ${ }^{3}$ Cardiorespiratory and Vascular Department, Countess of Chester NHS Foundation Trust Hospital, Countess of Chester Health Park, Chester, Cheshire, UK

\section{Correspondence to} Dr Peter J Angell, Research Institute for Sport and Exercise Sciences, Liverpool John Moores University, Tom Reilly Building, Byrom Street Campus, Liverpool L3 3AF, UK; P.Angell@2004.ljmu.ac.uk

Received 20 March 2012 Accepted 4 July 2012

\author{
Peter J Angell, ${ }^{1}$ Neil Chester, ${ }^{1}$ Nick Sculthorpe, ${ }^{2}$ Greg Whyte, ${ }^{1}$ Keith George, ${ }^{1}$ \\ John Somauroo ${ }^{1,3}$
}

\section{ABSTRACT}

The use of performance-enhancing and social drugs by athletes raises a number of ethical and health concerns. The World Anti-Doping Agency was constituted to address both of these issues as well as publishing a list of, and testing for, banned substances in athletes. Despite continuing methodological developments to detect drug use and associated punishments for positive dope tests, there are still many athletes who choose to use performance and image enhancing drugs. Of primary concern to this review are the health consequences of drug use by athletes. For such a large topic we must put in place delimitations. Specifically, we will address current knowledge, controversies and emerging evidence in relation to cardiovascular (CV) health of athletes taking drugs. Further, we delimit our discussion to the CV consequences of anabolic steroids and stimulant (including amphetamines and cocaine) use. These drugs are reported in the majority of adverse findings in athlete drug screenings and thus are more likely to be relevant to the healthcare professionals responsible for the wellbeing of athletes. In detailing CV health issues related to anabolic steroid and stimulant abuse by athletes we critique current research evidence, present exemplar case studies and suggest important avenues for on-going research. Specifically we prompt the need for awareness of clinical staff when assessing the potential CV consequences of drug use in athletes.

\section{INTRODUCTION}

In a bid to improve performance and/or aid recovery, various pharmaceutical products have been used, both openly (legally) and in a clandestine manner against the rules of governing bodies, by a broad array of athletes. ${ }^{1}$ The World Anti-Doping Agency (WADA) strictly regulates the use of pharmaceutical products in competitive sport. WADA produced and regularly updates the World Anti-Doping Code that includes a prohibited drug list. This list dictates what is and is not acceptable, from a doping perspective, within sport (table 1). The list has various subsections with some drugs banned both 'in' and 'out' of competition, while others are banned 'in' competition only (eg, ephedrine and the cannabinoids). The WADA list of prohibited substances is further broken down into several subcategories of specific products, including anabolic agents, peptide hormones and growth factors; $\beta$-2 agonists; hormone and metabolic modulators; diuretics and masking agents; stimulants; narcotics; cannabinoids; and glucocortocosteroids (table 1). Despite strict rules and punishments being in place in an attempt to limit doping offences, there continues to be those who choose to try and gain an unfair advantage in sport by taking drugs. ${ }^{3}$

As well as the concerns of WADA in defending the spirit of free and fair competition, awareness is also raised when there are known health consequences of drug abuse. The negative health consequences of doping for athletes and the education of support staff are the focus of this narrative review. Clearly, doping and athlete health is a vast area and so two points of delimitation are made up-front. First, we concentrate on cardiovascular (CV) health consequences of drug use. Second, this review focuses on anabolic agents and stimulants. According to WADA's adverse analytical findings report from 2010, anabolic agents accounted for around $60 \%$ of adverse findings, with stimulants contributing around $10 \% .{ }^{4}$ Consequently, the clinical support teams working with athletes must understand the potential CV health consequences when athletes abuse these drugs. Finally, we will discuss the CV effects of cocaine use, as it is one of the most widely used recreational drugs detected in athletes. ${ }^{4}$ As well as reflecting on previous data related to the $\mathrm{CV}$ health consequences of anabolic steroid, stimulant and cocaine use we have attempted to provide extra context and information in the form of brief case-study exemplars on anabolic steroid and cocaine abuse.

\section{ANABOLIC AGENTS}

There are a number of drugs that are used in an attempt to increase lean muscle mass. Of these, the most well known is the steroid hormone

Table 1 WADA prohibited substance list (Adapted from WADA 2012 Prohibited List $^{2}$ )

\begin{tabular}{|c|c|}
\hline Prohibited substance group & Examples \\
\hline Anabolic agents & $\begin{array}{l}\text { Anabolic androgenic steroids } \\
\text { Other anabolic agents; for } \\
\text { example, clenbuterol }\end{array}$ \\
\hline $\begin{array}{l}\text { Peptide hormones, Growth } \\
\text { factors and related substances }\end{array}$ & $\begin{array}{l}\text { Erythropoietin } \\
\text { Human chorionic gonadotrophin } \\
\text { Insulins and insulin-like growth } \\
\text { factors }\end{array}$ \\
\hline$\beta-2$ Agonists & $\begin{array}{l}\text { All except therapeutic doses of } \\
\text { salbutomol, formoterol and } \\
\text { salmeterol }\end{array}$ \\
\hline $\begin{array}{l}\text { Hormone and metabolic } \\
\text { modulators }\end{array}$ & Aromatase inhibitors \\
\hline Diuretics and masking agents & $\begin{array}{l}\text { Diuretics } \\
\text { Dextran }\end{array}$ \\
\hline Stimulants & $\begin{array}{l}\text { Amphetamine } \\
\text { Cocaine } \\
\text { Methamphetamine }\end{array}$ \\
\hline
\end{tabular}

WADA, World Anti-Doping Agency. 
testosterone $(\mathrm{T})$ and the various analogues that are based around testosterone, usually referred to as androgenic anabolic steroids (AS). In addition to AS there are non-steroid agents that are used in an attempt to generate the same anabolic effects. These include the $\beta-2$ agonist, clenbuterol (which is additionally used as an anorectic agent to reduce body fat), human growth hormone (HGH) and insulin/insulin-like growth factors. Other growth factors are commonly used in between courses of anabolic agent use and these include human chorionic gonadotropin (HCG) and erythropoietin (EPO) and more recently selective androgen receptor modulators. Whatever the classification, the purpose of anabolic and growth factors is to stimulate skeletal muscle growth and promote rapid recovery following intensive training. From a clinical perspective it is also worth noting that EPO is predominantly used to boost endurance exercise performance and in general has not crossed over to amateur and recreational sports performers. AS, HGH, HCG and insulin/insulin-like growth factors, however, are routinely used by professional, amateur and recreational athletes. ${ }^{5}$ Consequently, the likelihood of clinicians coming across users of these particular drugs is much greater.

It is worthy to note that the classification of AS covers a number of structural variants. Classically, AS are classified as water-soluble orally active forms (17- $\alpha$-alkylated) and lipid-soluble parenteral forms (17- $\beta$-esterified). In addition, they are often also classified as either testosterone-based, dihydrotestosterone-based (DHT) or 19-nortestosterone-based (Nandrolone) all of which have differing properties and expected side effects. The situation is further complicated by belief among users, often stemming from anecdotal advice, that some AS are better for predominantly 'bulking' (eg. Deca-Durabolin) while others are better suited to losing body fat or 'cutting' (eg. Winstrol). Users will often use these different forms of AS in varying quantities. The use of AS is also characterised by periods of use followed by periods of abstinence, or 'cycles'. This helps to maximise the effects of the drugs while also limiting the negative consequences and allowing the body to normalise following an 'on' cycle. Furthermore, users will often supplement their cycles with additional pharmaceutical agents both when bulking (eg, Insulin, human growth hormone) and when losing body fat (clenbuterol, cytomel, 2,4, dinitrophenol). Finally, there are a surprising number of drugs used to attempt to limit side effects of AS use or normalise the hypothalamo-pituitary-gonadal (HPG) axis following an AS cycle. These include estrogen receptor antagonists (tamoxifen), selective estrogen receptor inhibitors (clomifene), aromatase inhibitors (arimidex), $5-\alpha$ reductase inhibitors (finesteride) and HPG axis stimulators such as HCG.

Evidence of athlete use of AS has been available since the 1950 s with AS contributing to c. $60 \%$ of adverse findings according to recent WADA reports. ${ }^{6}$ In the general population there are data showing an increase in the prevalence of AS use. ${ }^{7}$ Despite such widespread use there is still some controversy as to the CV health consequences of taking AS. ${ }^{8}$ Large sample epidemiological evidence of the CV health consequences of longterm AS use is lacking, likely because of the reluctance to admit use and/or possession. In addition, evidence for a link between AS use and CV disease outcomes or end-points is mostly limited to case study reports. Published case studies include AS use associated with myocardial infarction, ${ }^{9}$ stroke, ${ }^{10}$ embolism $^{11}$ and other CV health issues (table 2). Although caution should be expressed in implying cause and effect from case studies, ${ }^{8}$ they can provide direction for case series and
Table 2 Cardiovascular events and risk factors from AS use

\begin{tabular}{lll}
\hline Event/risk factor & Case study & Cohort study \\
\hline Stroke & $\checkmark^{10}$ & $\mathrm{X}$ \\
Myocardial infarction & $\checkmark^{12}$ & $\mathrm{X}$ \\
Sudden death & $\checkmark^{13}$ & $\mathrm{X}$ \\
Thromboembolism & $\checkmark^{14}$ & $\mathrm{X}$ \\
Cardiac hypertrophy & $\checkmark^{15}$ & $\mathrm{X}$ \\
Cardiomyopathy & $\checkmark^{16}$ & $\mathrm{X}$ \\
Endocarditis & $\checkmark^{17}$ & $\mathrm{X}$ \\
Atrial fibrillation & $\checkmark^{18}$ & $\mathrm{X}$ \\
Heart failure & $\checkmark^{19}$ & $\mathrm{X}$ \\
Subdural haematoma & $\checkmark^{20}$ & $\checkmark^{22}$ \\
Elevated blood pressure & $\checkmark^{21}$ & $\boldsymbol{J}^{24}$ \\
Decreased HDL & $\checkmark^{23}$ & $\boldsymbol{J}^{25}$ \\
C-Reactive protein & $\mathrm{X}$ &
\end{tabular}

AS, anabolic steroids; HDL, high-density lipoprotein.

experimental studies as well as informing/educating clinical practitioners.

Significant research attention has focused on the impact of AS use on CV disease risk factors namely blood pressure, lipid profile, left ventricular (LV) mass, cardiac function and arterial function. Elevated systemic arterial blood pressure is associated with an increased CV disease risk. Compared to healthy controls, AS users have increased resting ${ }^{22} 26$ and exercise ${ }^{22}$ systolic blood pressure. Conversely, other studies have not observed increased blood pressure in AS user. ${ }^{6}{ }^{24}$ Differences in the training level of the participants along with age could be responsible for the differences seen in these studies.

AS have also been associated with negative alterations in lipid profiles. ${ }^{27}$ Changes reported include a decrease in high-density lipoprotein $(\mathrm{HDL}){ }^{28}$ an elevation in low-density lipoprotein $(\mathrm{LDL})^{24}$ and reduced apolipoprotein levels, ${ }^{29}$ possibly through up-regulation of hepatic triglyceride lipase. ${ }^{30}$ The changes in lipid profiles indicate an increase in atherosclerotic risk. Increases in homocysteine, a naturally occurring amino-acid thought to have a role in vaso-control, and C-reactive proteins (CRP), an acutephase protein that rises in response to inflammation, have been implicated as risk factors for CV disease. Grace and Davies ${ }^{25}$ demonstrated a significant increase in CRP in AS users. While Zmuda et al ${ }^{31}$ observed no significant increases in homocysteine in a group of AS users, Graham et a ${ }^{32}$ noted a significant elevation in homocysteine in AS users as well as those who had abstained from AS use for 3 months, indicating a possible effect of AS on vitamin B absorption. Previous studies have also suggested a possible link between AS use and thrombotic risk through alterations in haemoglobin levels. ${ }^{33}$

An increase in LV mass is an independent risk factor for CV disease. $^{34}$ AS use has been associated with an increase in LV mass, ${ }^{35} 36$ but there is conflicting data. ${ }^{27} 3738$ There are some data in AS users that suggest a reduction in systolic cardiac func$\operatorname{tion}^{38}$ although this is not a consistent finding between studies. ${ }^{8}$ A reduction in diastolic function has been observed more frequently and it has been suggested that a reduction in myocardial relaxation/elastance is associated with AS use. ${ }^{273738}$ AS use has also been associated with reduced endothelial function in conduit arteries. ${ }^{62439}$ Ebenbichler et al ${ }^{40}$ and Sader et al ${ }^{6}$ noted a reduced flow-mediated dilation in AS users as well as a reduced vasodilator response to glyceryl-trinitrate.

There is a growing evidence base that AS use can have a negative effect on multiple $\mathrm{CV}$ disease risk factors. We present 
a case study exemplar to illustrate the broad effect of AS use on the CV system.

\section{Case study 1}

A 25-year-old bodybuilder who was enrolled into a research study gave a detailed history of prolonged AS use. He selfreported no cardiac health problems. The participant was $1.93 \mathrm{~m}$ and $127 \mathrm{~kg}$ with an LV mass of $218 \mathrm{~g}$ on cardiac MRI. While absolute LV mass was high this was normalised when indexed for fat free mass. Left ventricular (LV) ejection fraction was normal (63\%), while right ventricular (RV) ejection fraction was slightly reduced at $49 \%$. LV diastolic function, measured using ultrasound echocardiography, was moderately depressed (significant increases in late atrial filling and tissue velocities). Heart rate was 75 beats per min and the ECG was unremarkable. Blood pressure was $131 / 71 \mathrm{~mm} / \mathrm{Hg}$. Total cholesterol was within normal clinical limits ( $4.6 \mathrm{mmol} / \mathrm{l})$, but high-density lipoproteins were significantly reduced in the participant at $0.46 \mathrm{mmol} / \mathrm{l}$. Low-density lipoproteins were above clinically acceptable levels at $3.77 \mathrm{mmol} / 1$. The participant had an elevated level of alanine transaminase indicative of reduction in liver function. In addition, both testosterone and sexhormone binding globulin were well below those expected within a male, at 2.13 and $6 \mathrm{nmol} / \mathrm{l}$, respectively. Gamma glutamyltransferase was not assessed. Based on changes to numerous CV risk factors, this athlete was informed of the test outcomes and was directed to seek a general practitioner consultation.

While recent data have started to paint a clearer picture of some of the negative CV consequences of AS use, longitudinal data are still lacking making the long-term chronic effects of AS use difficult to ascertain. ${ }^{8}$ There is also uncertainty in relation to the impact of withdrawal of AS use on CV risk factors. Inherently, the study of AS use is complicated by many factors. Specifically, most studies recruit diverse cohorts of self-selected AS users. In these groups there is likely great heterogeneity in total AS dose, poly-drug regimens employed as well the difficulty in verifying the 'true' dosages used. ${ }^{8}$

There is little direction given to clinicians and health practitioners regarding the identification of clandestine AS use. One of the reasons for athletes engaging in illicit AS use is that there are few 'tell tale' signs particularly in those sports where elevated strength and/or fat free mass is relatively commonplace. AS use occurs predominantly but not exclusively in strength and/or power athletes. Of the nine adverse findings for AS by the UK Anti-Doping Agency, three were from professional rugby players. ${ }^{41}$ It is worth noting that clinicians are far more likely to encounter recreational athletes using AS, training for predominantly aesthetic purposes. AS users may have rapid increases in lean mass, excessive hypertrophy of the trapezius, the shoulder musculature ${ }^{42}$ and a large neck circumference ${ }^{43}$ possibly due to higher androgen receptor levels. ${ }^{41}$ Other signs of AS use include puffy swelling around the face ${ }^{42}$ and acne which occurs in approximately $50 \%$ of users (including acne fulminans and acne conglobata). ${ }^{44}$ Consequently, clinicians may be suspicious of AS use in muscular individuals with acne (and/or scarring from previous eruptions) extending beyond the face to the back, chest and upper arms. ${ }^{44}$. Another common side effect of AS use is the development of female breast tissue (gynaecomastia) because of the aromotisation of AS to estrogen. The size and rate of development will vary depending on the type and duration of AS exposure with cases ranging from small areas of puffy tissue behind the nipple to easily recognisable breast tissue. It must be stressed however that these are general signs that may indicate AS use, but clinicians should be wary of unfairly targeting individuals who are simply prone to acne, or have a genetic basis for a muscular shoulder girdle.

\section{STIMULANTS-AMPHETAMINES}

Stimulants consist of psychoactive drugs, including amphetamines and its derivatives, as well as cocaine, caffeine and nicotine and are used to increase psychological activity, thereby inducing improvements in mental aptitude, physical function or both. Stimulants used for performance enhancement are typically those that affect the central nervous system (CNS); however, concurrent effects on the CV system are common. Amphetamines affect the CNS and autonomic nervous systems causing tachycardia and vasoconstriction as well as having psychological effects, increasing mental alertness and decreased fatigue. Cocaine has similar affects to amphetamines and also exerts its effect through the CNS causing an increase in the release of catecholamines, such as norepinephrine, as well as causing an increase of circulating dopamine. Ephedrine and its isomers are sympathomimetic agonists at both $\alpha$ - and $\beta$-adrenergic receptors and also have potent CV effects including increasing heart rate and blood pressure through vasoconstriction. The CV effects of stimulants have been shown to have a detrimental effect on CV health. ${ }^{45}$

There have been numerous reported cases of serious adverse CV events, including fatalities, linked with the use of ephedrine's. ${ }^{46} 47$ The use of ephedrine has also been linked to cardiomyopathy ${ }^{48}$ and stroke ${ }^{49}$ while pseudoephedrine use has also been linked with stroke ${ }^{50}$ and coronary artery spasm with myocardial infarction. ${ }^{51}$ Further, there are numerous case reports of significant cardiovascular events following the administration of over-the-counter stimulants. ${ }^{46}$ As with AS use, the interpretation of such case reports is difficult, since it may be that serious adverse events are as a consequence of preexisting medical conditions combined with drug use. What case studies do promote is further experimental study. For example, doses equivalent to three to four times greater than the recommended therapeutic dose of pseudoephedrine have raised diastolic blood pressure above $90 \mathrm{~mm} \mathrm{Hg}{ }^{52}$ These results were in accord with two other studies: Bye et al ${ }^{53}$ reported significant increases in heart rate and systolic blood pressure following relatively high doses of pseudoephedrine $(120$ and $180 \mathrm{mg})$; Empey et al ${ }^{54}$ noted that doses of 120 and $180 \mathrm{mg}$ produced statistically significant increases in both pulse and systolic blood pressure. The clinical relevance of these blood pressure changes is not known.

Reports of the CV effects of sympathomimetics in therapeutic doses have been conflicting. Bye et al ${ }^{53}$ observed that a single dose of ephedrine $(25 \mathrm{mg})$ significantly elevated both heart rate and systolic blood pressure while a single therapeutic dose of pseudoephedrine $(60 \mathrm{mg})$ significantly elevated only systolic arterial blood pressure. Bright et $a l^{55}$ and Empey et al ${ }^{54}$ noted little change in CV function following therapeutic doses. Increased blood pressure has been demonstrated in cases whereby ephedrine's have been co-administered with a moderate dose of caffeine. ${ }^{56}$ Caffeine is thought to exacerbate the action of ephedrine's since it too may cause vasoconstriction through antagonism of adenosine and release of catecholamines.

All stimulants structurally related to amphetamine can cause catecholamine-mediated cardiotoxicity. Increased catecholamine levels can lead to vasoconstriction, vasospasm, tachycardia and hypertension and it is as a result of these responses that oxygen supply to the heart is compromised and hypertrophy, fibrosis and necrosis can result. ${ }^{57}$ Clearly, such conditions develop over time, as a consequence of chronic exposure to 
amphetamines and the repercussions may include myocardial infarction, aortic dissection and sudden cardiac death. ${ }^{57}$

Little has been done by way of measuring both the acute/ chronic effects of stimulant use/abuse on a range of CV risk factors. While significant CV events are associated with their use, the effect on long-term atherosclerotic risk even with moderate usage, through negative alterations in known CV risk factors is worthy of further examination. With regard to amphetamines, emphasis has largely focused on the adverse effects relating to the CNS; however, it is clear that their effects can be wide-ranging and no less significant.

\section{STIMULANTS - COCAINE AND OTHERS}

Cocaine is one of the most frequently used recreational drugs worldwide. The prevalence of use in the UK has been steadily increasing over recent years with $6.6 \%$ of $16-24$ year olds admitting to regular use and figures suggesting over 1 million current cocaine users in the UK. ${ }^{58}$ Despite limited use as a performance-enhancing drug, there is still a relatively high level of adverse findings for cocaine use in athletes. According to WADA around $11.3 \%$ of adverse findings for stimulants were as a result of cocaine use. ${ }^{4}$ Athletes are not immune to the lure of social drugs like cocaine.

The use of cocaine has been associated with acute and chronic cardiovascular disease. ${ }^{59} 60$ Cocaine inhibits norepinephrine reuptake in the sympathetic system leading to overstimulation $^{60}$ and may cause release of catecholamines from central and peripheral stores. ${ }^{61}$ Acute coronary syndromes (including myocardial ischemia and infarction) are the commonest cardiac events secondary to cocaine abuse. ${ }^{60} 61$ This may be due to coronary artery spasm, increase in myocardial oxygen consumption from increases in heart rate and blood pressure, and a prothrombotic state. ${ }^{62}$ Most myocardial infarctions occur in the absence of atherosclerotic coronary disease and are unrelated to the dose and frequency of cocaine use. ${ }^{64}$ Cocaine abuse may however also lead to premature coronary disease sometimes with quite rapid onset. ${ }^{65}$ Cocaine abuse may also lead to coronary artery aneurysms, aortic dissection, rupture, vasculitis and stroke. ${ }^{66-68}$
Arrhythmias are not common with cocaine use, but sinus tachycardia, sinus bradycardia, supraventricular, ventricular arrhythmias and bundle branch blocks have been reported. ${ }^{59} 6970$ A dilated cardiomyopathy can be caused by cocaine use and a cocaine-induced myocarditis has been reported at postmortem in $20-30 \%$ of cases. ${ }^{71}$ Myocarditic changes, however, may be fully reversible if identified early and abstention from further cocaine abuse occurs. In the case study detailed the ECG changes with a significant cardiac event are shown in a young professional athlete who has a cocaine abuse history.

\section{Case study 2}

We briefly describe the case of a 27-year-old professional skater with a history of cocaine abuse. He developed retrosternal chest pain and ECG changes of inferolateral ST elevation (figure 1) after taking cocaine. His symptoms settled with nitrates and he developed T-wave inversion on his ECG the following day (figure 2) with a rise in Troponin I of $18.5 \mu \mathrm{g} / \mathrm{l}$. He had normal left ventricular systolic function on echocardiography. On cardiac catheterisation he had a smooth $40 \%$ stenosis in the ostial left anterior descending artery with the other coronary branches normal (figure 3). He was initially treated with antiplatelets, heparin and a $\beta$-blocker, but as it was felt that he had sustained a myocardial infarction due to coronary artery spasm, the $\beta$-blocker was substituted with a calcium channel blocker prior to discharge from hospital. He remained pain-free when further reviewed at 3 months.

While detection of cocaine use, unless openly admitted, can be problematic for the practitioner there are certain psychological and physiological indications that may help inform the healthcare provider. Cocaine use can produce euphoria, decreased appetite and need for sleep, but may also cause anxiety, irritability, paranoia and hallucinations. There may be associated tachycardia, sweating, pupil dilatation and nausea. Withdrawal after chronic use mainly causes psychological symptoms including depression, anxiety and increased sleep.

Other common stimulants used by athletes include caffeine and nicotine (from smoking tobacco, chewing tobacco and smoking cessation products). Both caffeine and nicotine have

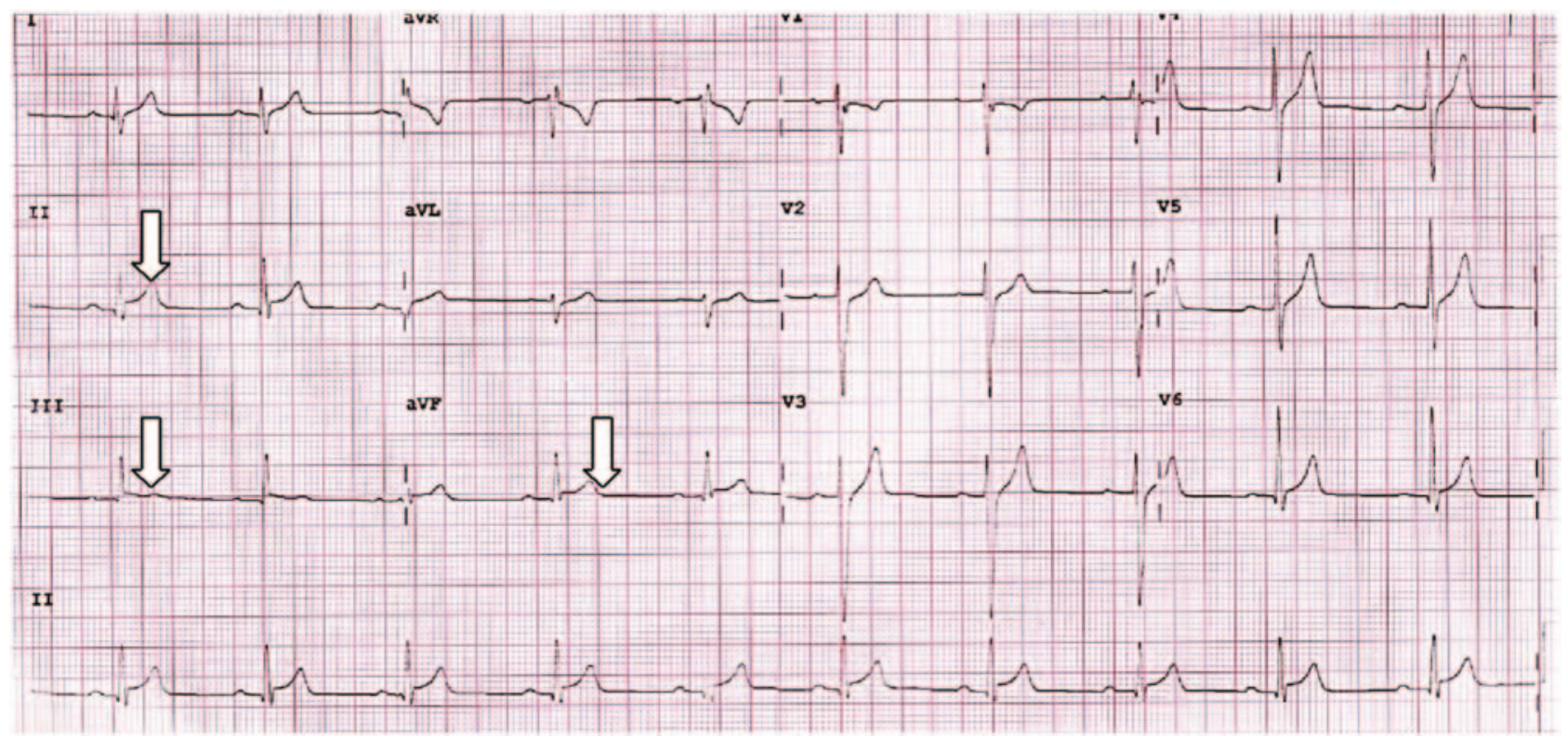

Figure 1 ECG 1: inferolateral ST elevation with chest pain. This figure is only reproduced in colour in the online version. 


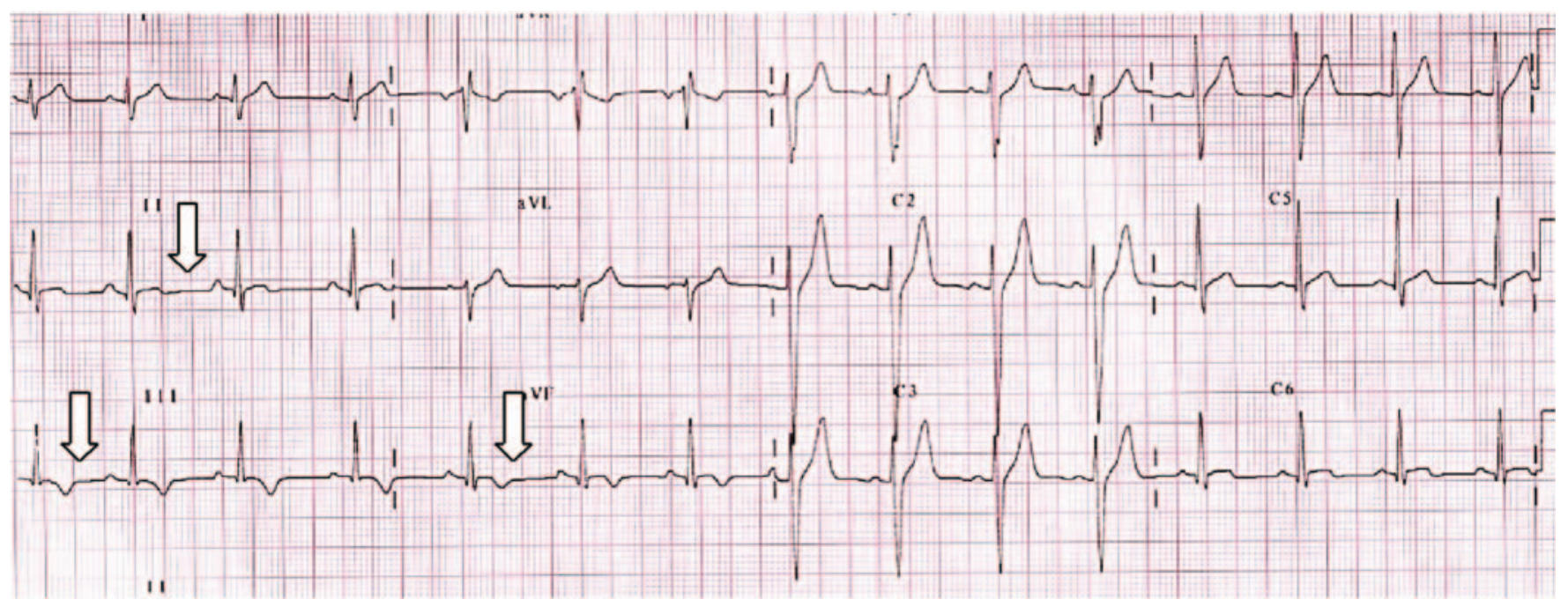

Figure 2 ECG 2: Inferior T-wave inversion with lateral biphasic T wave. This figure is only reproduced in colour in the online version.

been shown to have cardiac effects. Caffeine is used by athletes as a stimulant to decrease the feelings of fatigue and elevate heart rate and neural activity. The effect of caffeine will increase myocardial $\mathrm{O}_{2}$ and has been shown to increase blood pressure as well as raises the level of free-fatty acids in the blood, thereby increasing blood viscosity. If used in moderate doses there are minimal long-term side effects to caffeine use; however, extremely high doses have been associated with cardiac arrhythmias ${ }^{72}$ and events in otherwise healthy individuals. $^{73} 74$ Cigarette smoking has long been known to promote atherosclerosis, with an increased risk of sudden death, ${ }^{75}$ myocardial infarction ${ }^{76} 77$ and stroke. ${ }^{78}$ The use of nicotine therapies such as transdermal patches, inhalators and gum as well as the common use of chewing tobacco in some sports has also been associated with an increased cardiovascular event risk. ${ }^{79} 80$ Again, much of these data have come from case study and anecdotal data, with larger studies not observing a significant increase in risk of cardiovascular events. $^{81}$ Like most other stimulants further research is required and given that both caffeine and nicotine are not completely banned admission and monitoring of use may be easier than with other drugs.

\section{SUMMARY}

This review has attempted to describe available data and exemplar case studies detailing the potential CV health issues surrounding the use of some of the most common drugs detected in doping screens on athletes. Negative CV health effects do occur but more controlled research trials are required alongside longitudinal studies of chronic drug use. Available data demonstrate enough concern in relation to $\mathrm{CV}$ health and drug use that healthcare practitioners should be fully educated to help detect signs and symptoms and support athlete treatment and recovery where appropriate.

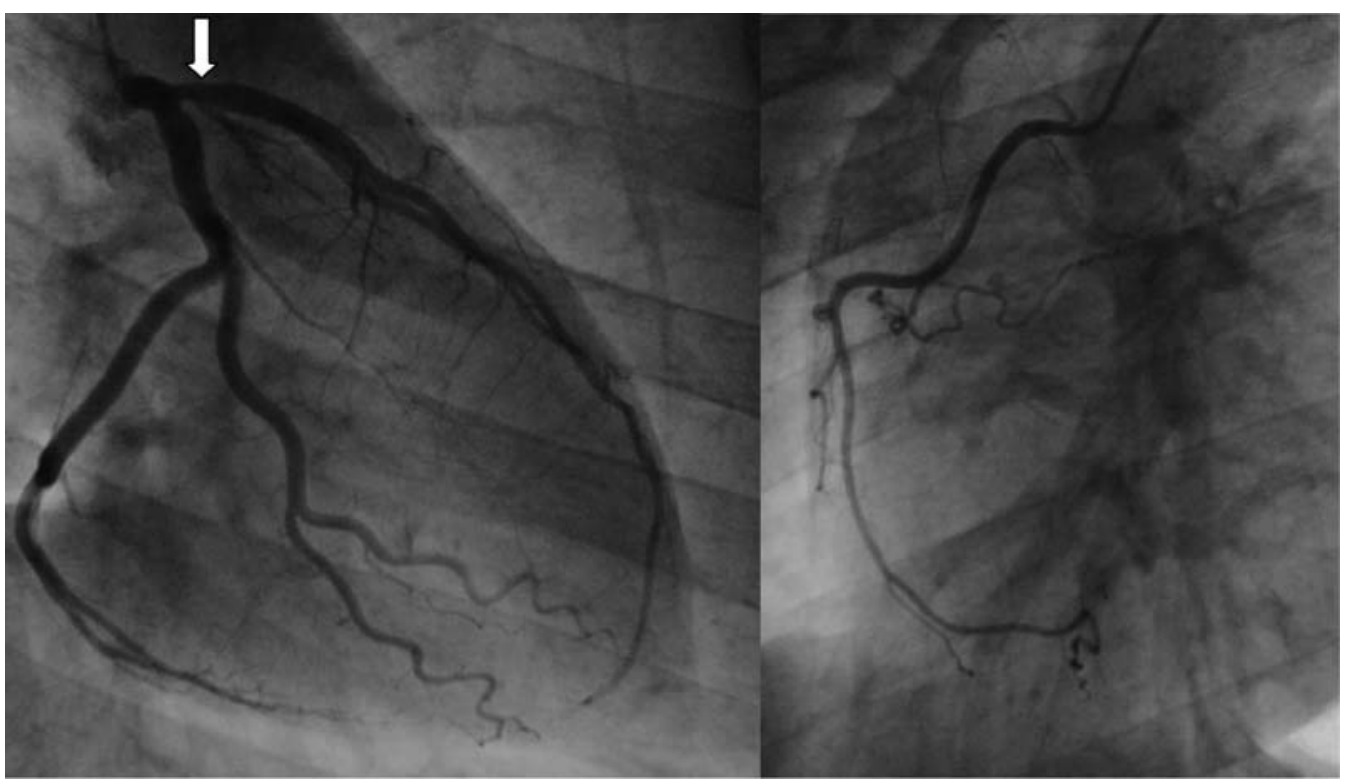

Figure 3 Coronary angiography: 40\% stenosis in ostial left anterior descending artery (arrow) with other coronary branches normal. 
Contributors All authors have contributed substantially to the conception and design of the paper with PJA, JS and KG contributing to data analysis and interpretation. All authors have also contributed significantly to the drafting and revising of the article before approving the final draft.

Competing interests None.

Patient consent Obtained.

Ethics approval Liverpool John Moores University.

Provenance and peer review Not commissioned; externally peer reviewed.

\section{REFERENCES}

1. Yesalis CE, Bahrke M. History of doping in sport. Performance enhancing substances in sport and exercise. Champaign: Human Kinetics, 2002:1-20.

2. WADA. The 2012 prohibited list International Standard. http://wwwwada-amaorg/ Documents/World Anti-Doping Program/WADP-Prohibited-list/2012/

WADA Prohibited List 2012 ENpdf (serial on the Internet), 2012.

3. Calfee R, Fadale P. Popular ergogenic drugs and supplements in young athletes. Pediatrics 2006:117:e577.

4. <WADA 2010_Laboratory_Statistics_Report.pdf >

5. Baker J'S, Graham MR, Davies B. Steroid and prescription medicine abuse in the health and fitness community: a regional study. Eur $\mathrm{J}$ Intern Med 2006:17:479-84

6. Sader MA, Griffiths KA, McCredie RJ, et al. Androgenic anabolic steroids and arterial structure and function in male bodybuilders. J Am Coll Cardiol 2001; 37:224-30

7. McVeigh J, Beynon C, Bellis MA. New challenges for agency based syringe exchange schemes: analysis of 11 years of data (1991-2001) in Merseyside and Cheshire, United Kingdom. Int J Drug Policy 2003;14:399-405.

8. Angell P, Chester N, Green D, et al. Anabolic steroids and cardiovascular risk. Sports Med 2012;42:119-34.

9. Appleby M, Fisher M, Martin M. Myocardial infarction, hyperkalaemia and ventricular tachycardia in a young male body-builder. Int J Cardiol 1994;44:171-4

10. Santamarina RD, Besocke AG, Romano LM, et al. Ischemic stroke related to anabolic abuse. Clin Neuropharmacol 2008;31:80-5.

11. Liljeqvist $\mathbf{S}$, Hellden A, Bergman U, et al. Pulmonary embolism associated with the use of anabolic steroids. Eur J Intern Med 2008:19:214-15.

12. Lunghetti S, Zaca V, Maffei S, et al. Cardiogenic shock complicating myocardial infarction in a doped athlete. Acute Card Care 2009;11:250-1.

13. Fineschi V, Riezzo I, Centini F, et al. Sudden cardiac death during anabolic steroid abuse: morphologic and toxicologic findings in two fatal cases of bodybuilders. Int $J$ Legal Med 2007;121:48-53.

14. Ment J, Ludman PF. Coronary thrombus in a 23 year old anabolic steroid user. Heart 2002;88:342

15. Mark PB, Watkins S, Dargie HJ. Cardiomyopathy induced by performance enhancing drugs in a competitive bodybuilder. Heart 2005;91:888.

16. Ahlgrim C, Guglin M. Anabolics and cardiomyopathy in a bodybuilder: case report and literature review. J Card Fail 2009:15:496-500.

17. Frogel JK, Weiss SJ, Kohl BA. Transesophageal echocardiography diagnosis of coronary sinus thrombosis. Anesth Analg 2009;108:441-2.

18. Sullivan ML, Martinez CM, Gallagher EJ. Atrial fibrillation and anabolic steroids. J Emerg Med 1999;17:851-7.

19. Clark BM, Schofield RS. Dilated cardiomyopathy and acute liver injury associated with combined use of ephedra, gamma-hydroxybutyrate, and anabolic steroids. Pharmacotherapy 2005;25:756-61.

20. Alhadad A, Acosta S, Sarabi L, et al. Pulmonary embolism associated with protein $\mathrm{C}$ deficiency and abuse of anabolic-androgen steroids. Clin Appl Thromb Hemost 2010;16:228-31.

21. Wysoczanski M, Rachko M, Bergmann SR. Acute myocardial infarction in a young man using anabolic steroids. Angiology 2008;59:376-8.

22. Riebe D, Fernhall B, Thompson PD. The blood pressure response to exercise in anabolic steroid users. Med Sci Sports Exerc 1992;24:633-7.

23. Gunes $\mathbf{Y}$, Erbas $\mathrm{C}$, Okuyan $\mathrm{E}$, et al. Myocardial infarction with intracoronary thrombus induced by anabolic steroids. Anadolu Kardiyol Derg 2004;4:357-8.

24. Lane HA, Grace F, Smith JC, et al. Impaired vasoreactivity in bodybuilders using androgenic anabolic steroids. Eur J Clin Invest 2006;36:483-8.

25. Grace $\mathbf{F M}$, Davies B. Raised concentrations of $\mathrm{C}$ reactive protein in anabolic steroid using bodybuilders. Br J Sports Med 2004;38:97-8.

26. Freed DL, Banks AJ, Longson D, et al. Anabolic steroids in athelics: crossover double-blind trial on weightlifters. Br Med J 1975:2:471-3.

27. Angell P, Chester N, Green DJ, et al. Anabolic steroid use and longitudinal, radial and circumferential cardiac motion. Med Sci Sports Exerc 2012:44:583-90.

28. Hartgens $\mathbf{F}$, Rietjens $\mathrm{G}$, Keizer HA, et al. Effects of androgenic-anabolic steroids on apolipoproteins and lipoprotein (a). Br J Sports Med 2004;38:253-9.

29. Hartgens F, Kuipers H. Effects of androgenic-anabolic steroids in athletes. Sports Med 2004:34:513-54.
30. Applebaum-Bowden D, Haffner SM, Hazzard WR. The dyslipoproteinemia of anabolic steroid therapy: increase in hepatic triglyceride lipase precedes the decrease in high density lipoprotein2 cholesterol. Metabolism 1987:36:949.

31. Zmuda JM, Bausserman LL, Maceroni D, et al. The effect of supraphysiologic doses of testosterone on fasting total homocysteine levels in normal men. Atherosclerosis 1997;130:199-202.

32. Graham MR, Grace FM, Boobier W, et al. Homocysteine induced cardiovascular events: a consequence of long term anabolic-androgenic steroid (AAS) abuse. $\mathrm{Br} \mathrm{J}$ Sports Med 2006;40:644-8.

33. Alen M. Androgenic steroid effects on liver and red cells. Br J Sports Med 1985;19:15-20

34. Savage DD, Levy D, Dannenberg AL, et al. Association of echocardiographic left ventricular mass with body size, blood pressure and physical activity (the Framingham Study). Am J Cardiol 1990:65:371-6.

35. Sachtleben TR, Berg KE, Elias BA, et al. The effects of anabolic steroids on myocardial structure and cardiovascular fitness. Med Sci Sports Exerc 1993:25:1240-5.

36. Nottin S, Nguyen LD, Terbah M, et al. Cardiovascular effects of androgenic anabolic steroids in male bodybuilders determined by tissue Doppler imaging. Am J Cardiol 2006;97:912-15.

37. D'Andrea A, Caso P, Salerno G, et al. Left ventricular early myocardial dysfunction after chronic misuse of anabolic androgenic steroids: a Doppler myocardial and strain imaging analysis. Br J Sports Med 2007;41:149-55.

38. Baggish AL, Weiner RB, Kanayama G, et al. Long-term anabolic-androgenic steroid use is associated with left ventricular dysfunction. Circ Heart Fail 2010;3:472-6.

39. Kasikcioglu $\mathbf{E}$, Oflaz $\mathrm{H}$, Umman B, et al. Androgenic anabolic steroids also impair right ventricular function. Int J Cardiol 2009;134:123-5.

40. Ebenbichler CF, Sturm W, Ganzer H, et al. Flow-mediated, endothelium-dependent vasodilatation is impaired in male body builders taking anabolic-androgenic steroids. Atherosclerosis 2001;158:483-90.

41. Anti-Doping U. UK National Anti-Doping Programme Quarterly Report. 2011.

42. George AJ. The anabolic steroids and peptide hormones. In: Mottram, D. Drugs in Sport, 2nd edn S 1996:173-18.

43. Hartgens F, Van Marken Lichtenbelt WD, Ebbing S, et al. Body composition and anthropometry in bodybuilders: regional changes due to nandrolone decanoate administration. Int J Sports Med 2001;22:235-41.

44. Melnik B, Jansen T, Grabbe S. Abuse of anabolicâ€ androgenic steroids and bodybuilding acne: an underestimated health problem. J Dtsch Dermatol Ges 2007;5:110-17.

45. Ghuran A, Nolan J. Recreational drug misuse: issues for the cardiologist. Heart 2000;83:627

46. Haller CA, Benowitz NL. Adverse cardiovascular and central nervous system events associated with dietary supplements containing ephedra alkaloids. N Engl J Med 2000;343:1833-8.

47. Shekelle PG, Hardy ML, Morton SC, et al. Efficacy and safety of ephedra and ephedrine for weight loss and athletic performance. JAMA 2003:289:1537.

48. To L, Sangster J, Rampling D, et al. Ephedrine-induced cardiomyopathy. Med J Aust 1980:2:35

49. Bruno A, Nolte KB, Chapin J. Stroke associated with ephedrine use. Neurology 1993;43:1313.

50. Cantu C, Arauz A, Murillo-Bonilla LM, et al. Stroke associated with sympathomimetics contained in over-the-counter cough and cold drugs. Stroke 2003;34:1667-72.

51. Wiener I, Tilkian AG, Palazzolo M. Coronary artery spasm and myocardial infarction in a patient with normal coronary arteries: temporal relationship to pseudoephedrine ingestion. Cathete Cardiovasc Diagn 1990;20:51-3.

52. Drew C, Knight G, Hughes D, et al. Comparison of the effects of D-(-)-ephedrine and $\mathrm{L}-(+)$-pseudoephedrine on the cardiovascular and respiratory systems in man. Br J Clin Pharmacol 1978:6:221.

53. Bye $\mathbf{C}$, Hill $H$, Hughes $D$, et al. A comparison of plasma levels of $L(+)$ pseudoephedrine following different formulations, and their relation to cardiovascular and subjective effects in man. Eur J Clin Pharmacol 1975:8:47-53.

54. Empey D, Young G, Letley E, et al. Dose-response study of the nasal decongestant and cardiovascular effects of pseudoephedrine. Br J Clin Pharmacol 1980:9:351.

55. Bright T, Sandage B, Fletcher H. Selected cardiac and metabolic responses to pseudoephedrine with exercise. J Clini Pharmacol 1981:21:488.

56. Haller CA, Jacob P, Benowitz NL. Pharmacology of ephedra alkaloids and caffeine after single-dose dietary supplement use. Clini Pharmacol Ther-St Louis-. 2002; 72:421-32.

57. Kaye S, McKetin R, Duflou J, et al. Methamphetamine and cardiovascular pathology: a review of the evidence. Addiction 2007;102:1204-11 [Research Support, Non-U.S. Gov't Review]m

58. Fletcher K, Collinson J. Cracking down on the problem. Br J Cardiol 2011;18:102-3.

59. Lange RA, Hillis LD. Cardiovascular complications of cocaine use. N Engl J Med 2001:345:351-8.

60. Schwartz BG, Rezkalla S, Kloner RA. Cardiovascular effects of cocaine. Circulation 2010:122:2558-69.

61. Maraj S, Figueredo VM, Lynn Morris D. Cocaine and the heart. Clin Cardiol 2010:33:264-9. 
62. Lange RA, Cigarroa RG, Yancy CW Jr, et al. Cocaine-induced coronary-artery vasoconstriction. N Engl J Med 1989;321:1557-62.

63. Heesch CM, Wilhelm CR, Ristich J, et al. Cocaine activates platelets and increases the formation of circulating platelet containing microaggregates in humans. Heart 2000;83:688.

64. Hollander JE, Hoffman RS. Cocaine-induced myocardial infarction: an analysis and review of the literature. J Emerg Med 1992;10:169-77.

65. Dressler FA, Malekzadeh S, Roberts WC. Quantitative analysis of amounts of coronary arterial narrowing in cocaine addicts. Am J Cardiol 1990;65: 303-8.

66. Satran A, Bart BA, Henry CR, et al. Increased prevalence of coronary artery aneurysms among cocaine users. Circulation 2005;111:2424-9.

67. Hsue PY, Salinas CL, Bolger AF, et al. Acute aortic dissection related to crack cocaine. Circulation 2002:105:1592-5.

68. Martinez N, Diez-Tejedor E, Frank A. Vasospasm/thrombus in cerebral ischemia related to cocaine abuse. Stroke 1996;27:147.

69. Nanji AA, Filipenko JD. Asystole and ventricular fibrillation associated with cocaine intoxication. Chest 1984;85:132-3.

70. Isner JM, Chokshi SK. Cardiovascular complications of cocaine. Curr Probl Cardiol 1991;16:89.

71. Hogya PT, Wolfson AB. Chronic cocaine abuse associated with dilated cardiomyopathy. Am J Emerg Med 1990;8:203
72. Mehta A, Jain AC, Mehta MC, et al. Caffeine and cardiac arrhythmias. An experimental study in dogs with review of literature. Acta Cardiol 1997; 52:273.

73. Berger AJ, Alford K. Cardiac arrest in a young man following excess consumption of caffeinated 'energy drinks'. Med J Aust 2009;190:41-3.

74. Forman J, Aizer A, Young CR. Myocardial infarction resulting from caffeine overdose in an anorectic woman. Ann Emerg Med 1997;29:178-80.

75. Hallstrom AP, Cobb LA, Ray R. Smoking as a risk factor for recurrence of sudden cardiac arrest. N Engl J Med 1986;314:271-5.

76. Sugiishi M, Takatsu F. Cigarette smoking is a major risk factor for coronary spasm. Circulation 1993;87:76-9.

77. Newby DE, Wright RA, Labinjoh C, et al. Endothelial dysfunction, impaired endogenous fibrinolysis, and cigarette smoking: a mechanism for arterial thrombosis and myocardial infarction. Circulation 1999:99:1411-15.

78. Wolf PA, D'Agostino RB, Kannel WB, et al. Cigarette smoking as a risk factor for stroke. JAMA 1988;259:1025-9.

79. Ottervanger JP, Festen JM, de Vries AG, et al. Acute myocardial infarction while using the nicotine patch. Chest 1995;107:1765-6.

80. Arnaot MR. Treating heart disease. Nicotine patches may not be safe. BMJ 1995;310:663.

81. Joseph AM, Norman SM, Ferry LH, et al. The safety of transdermal nicotine as an aid to smoking cessation in patients with cardiac disease. N Engl J Med 1996;335:1792-8. 